\title{
$\int$ ornando-se Adulto: uma Abordagem Antropológica sobre Crianças e Religião
}

Flávia Pires

\section{Introdução}

Este artigo é resultado de uma pesquisa de campo de quase catorze meses (2000-2005), que culminou com a redação de uma tese de doutorado ${ }^{1}$. O trabalho de campo foi realizado na cidade de Catingueira " localizada no semiárido nordestino, no estado da Paraíba. O IBGE estimou para esse município uma população de 5.006 habitantes em 2009, distribuídos entre as zonas rural e urbana. Os católicos são, em grande medida, considerados a maioria, embora a presença neopentecostal venha abalando essa hegemonia, em um processo semelhante àqueles trabalhados por Regina Novaes (2000). Não há dados etnográficos que confirmem a presença dos sem religião, enquanto categoria do IBGE. A presença espírita está associada ao kardecismo e se dá, muitas vezes, em parceria com a pertença católica².

Durante a pesquisa, trabalhamos com crianças dos três aos treze anos de idade, além de adultos e idosos, na tentativa de compor um quadro, no qual as gerações seriam levadas em consideração, analisando-se, assim, o entendimento e a experiência religiosa naquela comunidade, principalmente a partir do ponto de vista das crianças ${ }^{3}$. Durante o trabalho de campo, as crianças eram incentivadas a desenhar e a escrever, tanto sobre temas livres, quanto partindo de assuntos propostos pela pesquisadora. Foi feito um exercício metodológico com essas crianças, tomando-se dois temas 
específicos ("O mal-assombro" e "A minha religião") nas duas escolas da cidade4. Colheu-se pelo menos vinte desenhos e redações de cada faixa etária citada em relação a cada um desses temas. Após a interpretação dos mesmos pelas crianças, os materiais produzidos foram classificados pela pesquisadora e depois analisados comparativamente ${ }^{5}$. Neste artigo trataremos, primordialmente, dos duzentos e noventa e sete desenhos e redações produzidos sob o título "A minha religião".

\section{Contextualização teórica}

As abordagens científicas que relacionam religião e infância não são abundantes. Localizamos alguns estudos que se concentram numa interface entre religião e infância, embora não se restrinjam à Antropologia (Astuti 2007; Astuti \& Harris 2008; Coles 1990; Bovet 1928; Elkind 1978; Garbarino 1996; Hardman 1999; Heller 1986; Nesbitt 1993, 2000a, 2000b; Robinson 1977). Segundo Nesbitt (2000), os estudos sobre crianças e religião concentram-se em uma abordagem quantitativa e altamente psicológica, citando-se Bushnell (1967), Anthony (1971), Gates (1976, 1982), O’Keeffe (1986), Bullivant (1987), Francis (1987), Hyde (1990), Lall (1999), Davies (1997), como referências na área. Há, no entanto, um campo de estudos sobre educação religiosa ou espiritual que conta inclusive com alguns periódicos como Religious Education, British Journal of Religious Education e The International Journal of Children's Spirituality.

Alguns pesquisadores discorreram sobre uma suposta impossibilidade de estudar a vida religiosa das crianças pequenas tomando-as como interlocutoras.

O trabalho descrito por Edward Robinson em The Original Vision (1977:11) sugere que as pessoas que se lembram de terem tido alguma consciência espiritual na sua infância eram geralmente incapazes de falar sobre o fato. Além disso, muitas dessas pessoas também disseram que foi apenas quando elas se tornaram adultas que reconheceram a importância desses eventos. Isso parece sugerir que qualquer tentativa de discutir assuntos "espirituais" com crianças muito pequenas é infrutífera (McCreery 1996:197, tradução livre).

Ronald Goldman vai ainda mais longe e descreve:

Percepções e conceitos religiosos não são baseados em dados sensoriais diretos, mas são formados a partir de outras percepções e conceitos de experiência. Os místicos, que afirmam terem sensações divinas diretas, são exceções, mas como eles são casos extremamente raros, ainda mais raros na adolescência e praticamente desconhecidos na infância, nós não precisamos explorar a sua significância (1964:14, tradução livre). 
Goldman não acredita ser possível realizar tal empreendimento de pesquisa porque, segundo ele, as crianças pequenas não teriam ainda formados os conceitos ou percepções religiosas: "o insight religioso geralmente começa a aparecer entre os doze e os treze anos de idade" (1964:226, tradução livre).

Algumas pesquisas apostam, no entanto, na validade de estudos sobre religião que tenham como foco as crianças. É o caso de Hay \& Nye (2006 [1998]), que, preocupados em estudar a educação espiritual, afirmam que as crianças têm experiências religiosas mais intensas que os adultos porque naturalmente os seres humanos são equipados com uma consciência religiosa que vai sendo esquecida com o passar dos anos ${ }^{6}$. Para Robinson (1977), por sua vez, a experiência religiosa, denominada "a visão original", é uma experiência ordinária que ocorre de primeira mão e, por isso, de maneira mais completa na infância. Como na experiência mística, o sujeito sente que foi abalado por um poder maior que ele próprio. Para o autor, essa experiência é essencial para o desenvolvimento do entendimento maduro, não se tratando de fantasia, mas sim de uma forma de conhecimento.

Creio que o que tenho chamado de "a visão original" da infância não é mera fantasia imaginativa, mas uma forma de conhecimento e que é essencial para o desenvolvimento de uma compreensão madura (:16, tradução livre).

No Brasil, há pesquisas em andamento que tencionam compreender como as crianças se inserem na vida religiosa. O campo de estudos é recente, mas promissor (Falcão \& Campos 2009; Bergo \& Gomes 2009; Campos et al 2010).

Outro problema recorrente no estudo das crianças, como afirmam Robinson (1977) e James, Jenks \& Prout (1998:183), é que muitos pesquisadores sentem-se autorizados a expressar sua opinião, como se o fato de já terem sido crianças os autorizasse a teorizar sobre a infância. Outro problema recorrente da literatura sobre o tema é considerar a memória, através dos relatos sobre a infância, como a própria expressão da voz das crianças, como fez o próprio Robinson (1977). Para se estudar as ideias e experiências infantis é preciso estudar as crianças propriamente ditas, e não o que os adultos têm a dizer sobre a sua infância ou a dos seus filhos. Não afirmamos, todavia, que se devam excluir os adultos das pesquisas sobre infância. Um estudo verdadeiramente antropológico deve incluir as crianças como sujeitos sociais e agentes históricos, mas relacionando-as aos outros grupos sociais (Toren 1999; Pires 2007b; Campos et al 2010).

\section{Práticas e intenções}

Antes de mais nada, sem nos dedicarmos a realizar uma exegese da noção de simbólico, trataremos de conceitualizá-la operacionalmente para atender aos objetivos do artigo. Normalmente, entende-se o simbólico como uma representação de algo 
que não está contido no símbolo, que o extrapola, mas que pode ser acessado através dele. O simbólico é metafórico, não diz respeito ao símbolo mesmo, mas a uma outra ordem de realidade que lhe é superior. Nesse sentido, a cruz representa a religião cristã, simbolizando-a. A cruz, as autoridades eclesiásticas, a Bíblia, as imagens dos santos, os hinos etc. são símbolos que correspondem a determinadas religiões. A ideia aqui defendida é a de que as crianças não trabalham com os símbolos da mesma forma que os adultos. Elas os reconhecem, mas não como realidades que representam algo que está além delas mesmas. Os símbolos são tomados por sua materialidade; por exemplo: o Divino Espírito Santo, símbolo conhecido pelas crianças, é de fato um passarinho, que voa, põe ovo e canta, como um pássaro comum. Veremos com mais detalhes que o simbólico, enquanto realidade que ultrapassa o que é representado, se constrói como uma forma de classificação do mundo bastante corrente entre os adultos, mas inexistente entre as crianças.

Das ocorrências observadas nos desenhos e redações das crianças sobre o tema "A minha religião", chama a atenção o número elevado de igrejas, como é possível observar no gráfico abaixo (Soma das Igrejas $^{1}$ ).

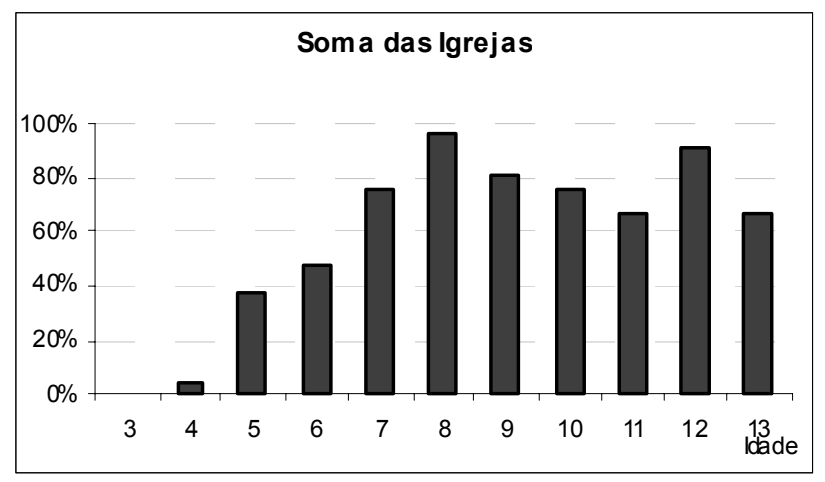

Uma das hipóteses deste trabalho é que, a julgar pela quantidade massiva de desenhos de igrejas, podemos dizer que a religião, para as crianças, está de alguma forma relacionada à igreja. Se por um lado religião se liga à figura da igreja para as crianças, o entendimento do que a igreja representa vai mudando à medida que a idade da criança varia. Nos primeiros anos pesquisados os desenhos apresentam a igreja "solta" na folha de papel, sem qualquer outro desenho associado. Com o passar dos anos a igreja vai frequentemente aparecer acrescida de elementos contextuais, dos quais se destaca a cidade que a rodeia, com sua praça, cruzeiro, ruas. Com o aumento da idade, a igreja é associada aos eventos que ali têm lugar, notadamente, a festa do padroeiro, casamentos, missas, cultos - e vemos aí a presença de pessoas. 
Athilson, 7 a. (conoinba)

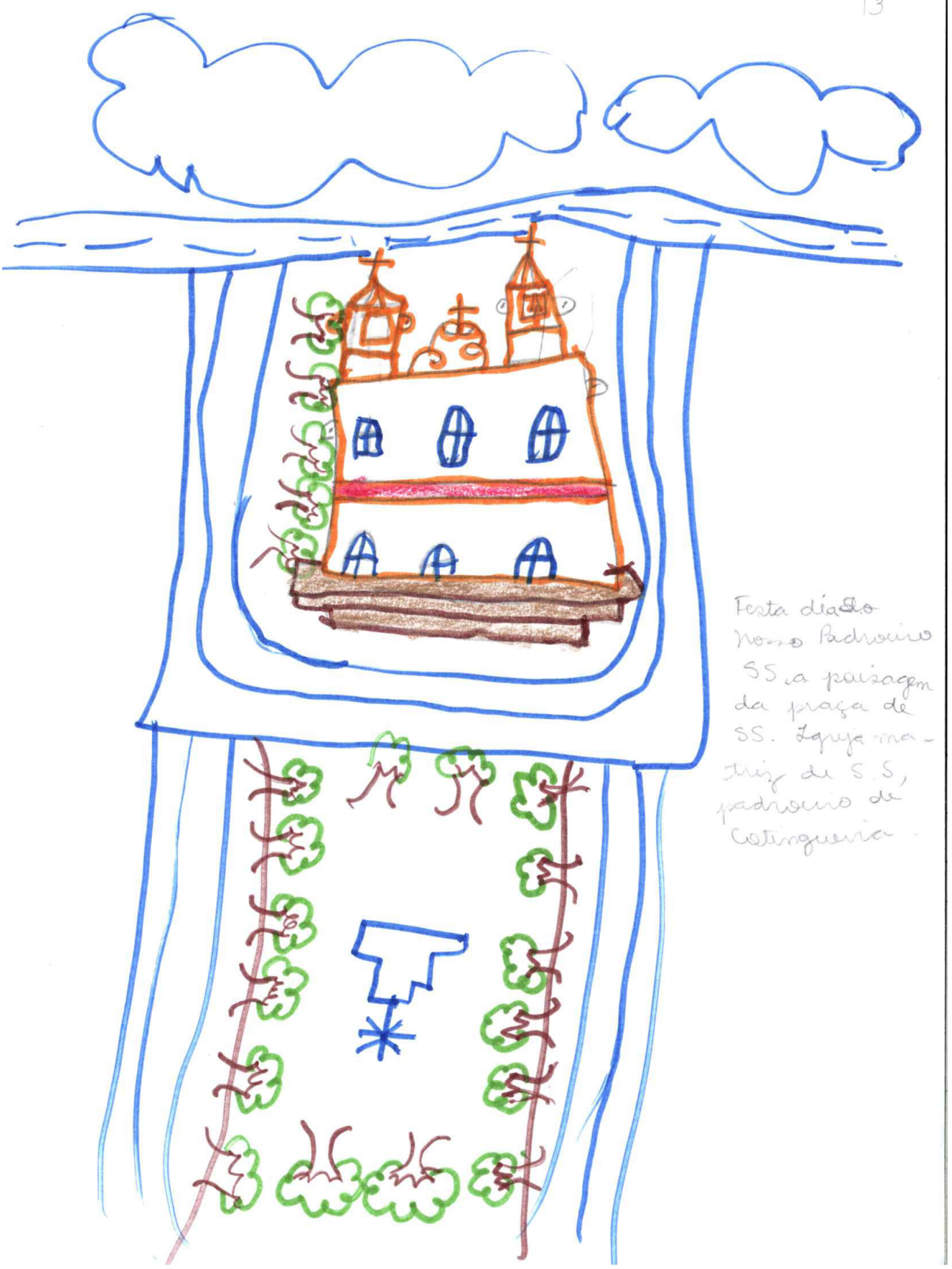

Menino, 7 anos de idade (igreja no contexto da cidade, com nuvens, ruas, árvores e o cruzeiro da praça) 


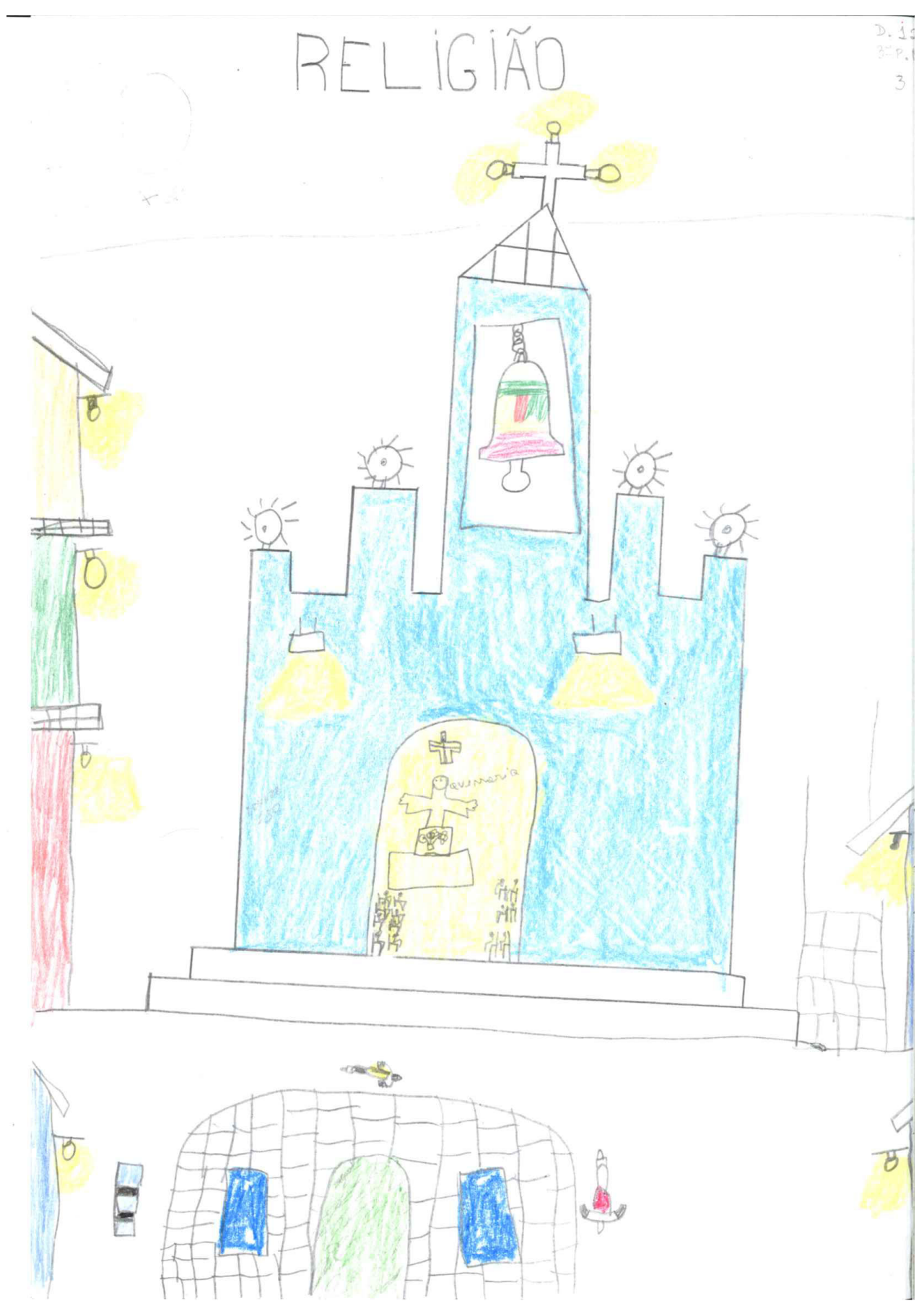

Menino, 12 anos de idade

(a igreja novamente contextualizada, com a presença de pessoas e a celebração de uma missa) 
Pode-se questionar com que conceito de igreja essas crianças estão dialogando. Seria ir longe demais afirmar que as crianças pequenas não reconhecem a natureza do comparecimento à igreja como distinta do cotidiano? Acreditamos que não. Tudo se passa como se para as crianças pequenas não houvesse distinção entre uma atitude religiosa e outra não religiosa. Dessa forma, ouvir música fora ou dentro da igreja, assim como assistir a um filme na televisão ou assistir à missa, constituiriam atividades similares. Nessa direção, um menino evangélico de 8 anos de idade, enquanto desenhava o pastor, escreveu: "Eu gosto mais ou menos de ir à igreja. Vim [sic] aqui é muito legal. Você dá folha para a gente desenhar", referindo-se às atividades feitas na casa da pesquisadora. A frase da criança parece corroborar a afirmação de que não há diferença ontológica entre ir à igreja e ir à casa de alguém, ao sugerir a não singularidade do frequentar à igreja e a indistinção entre os mundos cotidiano e religioso. (Interessante constatar que, no caso específico dos evangélicos, o mesmo ocorreria também com os adultos, já que a ideia da igreja enquanto espaço sagrado em si mesmo parece ser predominantemente católica). Sugere-se a hipótese de que o mais importante para as crianças é a atividade em si mesma. Elas não estariam nem um pouco preocupadas com o que há por trás, por exemplo, de uma missa, senão com o ato em si. Com isso, não afirmamos que a prática religiosa não tenha consequências para a criança, ou que a religião das crianças implique exterioridade subjetiva. Uma vez que as crianças participam ativamente da vida religiosa da cidade, estando sempre presentes nos diversos eventos promovidos, elas certamente são parte importante das religiões, como mostram também Falcão \& Campos (2009) e Bergo \& Gomes (2009) no caso das religiões afro-brasileiras. Por isso, vale a pena observar como elas se inserem nesse universo.

As crianças nunca vão aos eventos religiosos sozinhas: sempre lhes acompanham a família ou os amigos. Geralmente, as crianças colocam a sua melhor roupa para irem à missa ou ao culto. Não é raro ver meninas nas igrejas vestidas com trajes de damas de honra, que embora sejam, sem dúvida, antigos, estão lavados e passados com esmero. $\mathrm{Na}$ reunião espírita, as crianças não são muito assíduas ${ }^{8}$, mas observa-se, de modo geral, maior simplicidade da indumentária no centro espírita, com relação tanto à igreja católica quanto às igrejas evangélicas. Por exemplo: tanto os adultos quanto as crianças são facilmente vistos calçando chinelos na reunião espírita, o que é mais raro nas outras religiões. De maneira geral, nos serviços religiosos as crianças católicas são as mais bem arrumadas, seguidas das evangélicas e, finalmente, das espíritas. Nos eventos religiosos infantis, a indumentária e o cuidado pessoal parecem seguir padrões similares aos dos adultos $^{9}$. No entanto, seria correto afirmar, no caso das três religiões, que, apesar de muitas crianças comparecerem aos eventos infantis calçando chinelos, apresentar-se descalço seria considerado inadequado. Muitas crianças vestem roupas perceptivelmente gastas, mas nunca se apresentariam com roupas sujas. Que a criança se suje sem querer no caminho para o serviço religioso é perdoável, mas que não tenha tomado banho antes de sair de casa é inadmissível. Não tomar banho, usar roupa suja ou comparecer descalço seriam consideradas atitudes inadmissíveis em quaisquer das três religiões. Para 
comparecer aos eventos religiosos, tanto infantis quanto adultos, é essencial ter tomado banho. É desejável que quando a criança chegue ao serviço religioso o seu cabelo ainda esteja molhado, evidenciando que ela, por assim dizer, "acabou de sair do banho". Passar perfume, da mesma maneira, é altamente recomendável para crianças e adultos. Assim, fica claro que há um código especial de indumentária requerido em todos os serviços religiosos das três religiões em questão. Com o tempo, a criança vai tomando ciência de que, para ir à igreja ou ao centro, é necessário se arrumar devidamente. Ela aos poucos entenderá que não se trata de uma atividade ordinária, mas sim de uma atividade mais importante que qualquer outro comprometimento. Com o tempo, ela não vai mais precisar da ordem da mãe para parar a brincadeira e ir tomar o banho, quando a hora da missa, por exemplo, se aproxima. Por mais que as crianças não saibam que o Divino Espírito Santo é a terceira pessoa da Trindade, elas aos poucos vão tomando conhecimento de que devem se apresentar bem vestidas na igreja. Dentre outras coisas, elas vão aprendendo que existe algo na igreja que não pode ser encontrado fora dela. Em outras palavras: que o edifício (construção física) não encerra a ontologia da igreja, ou seja, que a igreja simboliza algo para além da construção física, do prédio.

A partir de uma evidência etnográfica, vamos agora perscrutar as intenções infantis em relação ao frequentar a igreja. Pelo menos seis crianças, nas idades de nove, dez e treze anos de idade, desenharam igrejas que elas não frequentam: católicos desenharam igrejas "crentes" e evangélicos desenharam igrejas católicas. Quando lhes perguntei o porquê do desenho, elas disseram que tinham vontade de ir àquelas igrejas e que tinham feito pensando nas outras crianças que as frequentam. Mas por que ir àquela igreja específica?, insisti. No caso dos que desenharam igrejas evangélicas, as crianças afirmaram que gostariam de ir para ouvir e cantar os hinos. E para ver as imagens dos santos e "como é a missa", no caso dos evangélicos que desenharam igrejas católicas. Perguntei por que elas não iam e elas me disseram unanimemente que suas mães as proibiam. Quiçá possamos afirmar, a partir desse dado etnográfico, que as crianças pequenas não parecem diferenciar os credos, não porque não sejam capazes de fazê-lo (é evidente que podem distingui-los), mas porque tomam as igrejas antes pelo que as une, desconsiderando a diversidade e concentrandose na unidade das igrejas ${ }^{10}$.

É relevante destacar que o convívio das crianças pertencentes aos diversos credos representados na cidade parece ocorrer de forma harmônica durante a primeira infância. Manifestações de repúdio à religião alheia só foram observadas depois dos nove anos de idade (Pires 2007a:154-184). Essas manifestações negativas passam a acontecer justamente quando a criança toma conhecimento da singularidade da sua igreja, concomitantemente ao processo de entendimento da categoria do simbólico, que será melhor analisado adiante. Como vemos no desenho abaixo, a criança não apenas escreve o nome do santo que identifica a igreja católica, como acrescenta: "Essa é a minha igreja da minha cidade" (grifo nosso). Esse tipo de atitude não é comum antes dos nove anos de idade, momento em que religião é representada principalmente pela igreja, não identificada com nenhum credo, mas tomada somente enquanto prédio, templo, edifício que compõe a paisagem da cidade. 


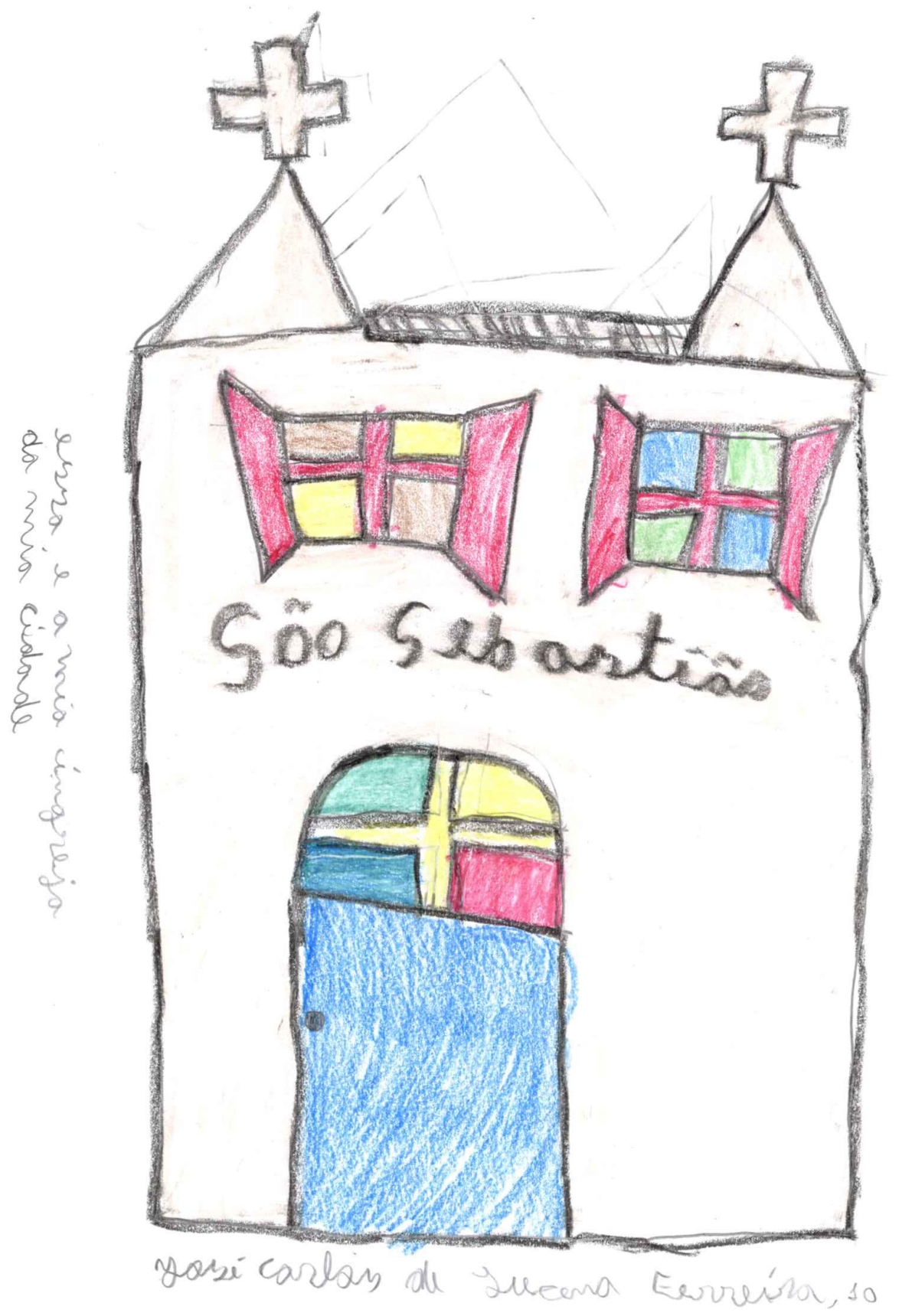

Menino, 10 anos de idade 


\section{A irrelevância do simbólico}

Christina Toren, antropóloga australiana radicada no Reino Unido e que vem trabalhando com crianças nas suas etnografias, parece fornecer-nos algumas pistas sobre como analisar teoricamente o material de pesquisa apresentado. Ao investigar como as crianças e os adultos concebem a hierarquia, conceito central para se compreender a moralidade fijiana, Toren (1999) chegou a conclusões estimulantes para aqueles interessados na análise do simbólico. A autora utilizou desenhos préelaborados nos quais as crianças deveriam indicar o chefe, as mulheres, as crianças, os homens, os idosos, e assim por diante. As suas conclusões apontam que, para os adultos, a hierarquia define a posição geográfica de uma pessoa nas variadas situações de interação social, inclusive o ritual. Para as crianças, por sua vez, é a posição geográfica que define o status hierárquico. Em outras palavras, para os pequenos o chefe é chefe porque se senta acima e para os adultos o chefe é chefe, logo se senta acima. Veja que a percepção adulta inverte a ideia infantil. Algo parecido poderia ser pensado com relação aos dados coletados em Catingueira. As crianças catingueirenses diriam: "Eu vou à igreja porque meu irmão vai"; enquanto seria possível ouvir de um adolescente ou adulto: "Eu vou à igreja porque sou uma pessoa religiosa", ou "porque sou evangélico". Em poucas palavras: quando criança, o credo ou o objeto religioso eram tidos como irrelevantes. Quando adulto, entretanto, a religião parece tornar-se a grande razão do comparecimento à igreja. Existem, com certeza, outros motivos que levam uma pessoa adulta a comparecer à igreja, como, por exemplo, a sociabilidade. Nas conclusões retomaremos esta ideia. No entanto, estamos destacando que o elemento mais importante a ser elencado pelo sujeito adulto parece ser uma razão de cunho religioso. Não que outras justificações não se apresentem, mas o que estamos ressaltando é a mudança que ocorre no processo de tornar-se adulto. Quando criança, "religião" não faz sentido senão em referência à igreja (prédio) " que, por sua vez, independe dos diferentes credos, como vimos nos desenhos das crianças que enfatizaram igrejas a que não pertencem.

Seguindo as sugestões de Toren (1999), poderíamos argumentar que para os adultos ir à igreja simboliza algo que ultrapassa o aspecto prático do ato. Ou seja, para uma mãe, ir à igreja "significa" ou "simboliza" algo que se torna o verdadeiro motivo desse evento. Ao contrário do seu filho, ela vai à igreja por alguma razão, seja para rezar, se encontrar com Deus ou consigo mesma, pedir perdão pelos pecados, pagar promessa, ou até mesmo para observar as roupas das outras mulheres. Note-se que nem sempre os motivos dos adultos para frequentarem a igreja são de natureza abstrata. Importante enfatizar que não estamos apenas tomando a distinção abstrato versus concreto como eixo para entender como os adultos e as crianças se relacionam com a religião. De fato, a vivência religiosa se dá na infância através da concretude do comparecer à igreja; no entanto, como isso implica uma rede de relações sociais e de atitudes especiais, não podemos falar de um "simples" aspecto concreto. O concreto 
para a criança não é nada simples. É, por assim dizer, tão complexo quando o simbólico para o adulto. Para as crianças, é completamente diferente "frequentar a igreja parece vir antes da sua cognição de significado. Quando criança, apenas frequenta-se a igreja, depois é que surgem as questões teológicas, morais e propriamente religiosas que permeiam a atitude, além das "consequências" do ato (ir à igreja católica como parte do processo de tornar-me um católico, por exemplo).

Assim, o adulto vai à igreja católica porque é católico, já a criança se torna católica porque vai à igreja católica, da mesma maneira que poderia tornar-se evangélica ou espírita. Para as crianças, o catolicismo (ou o kardecismo, ou o neopentecostalismo) não vêm antes da igreja (templo, prédio), como é o caso com os adultos. O que enfatizamos aqui é a ordem dos fatores, que parece ser totalmente diferente para adultos e crianças. Dessa forma, não estamos de maneira alguma afirmando que o adulto é um espelho da criança ${ }^{11}$; somente tencionamos mostrar como crianças e adultos trabalham com entendimentos diferenciados em relação à religião. Que as crianças não trabalhem com o aspecto simbólico da religião não nos leva a inferir uma incapacidade de questionar os ensinamentos religiosos ou de refletir sobre eles, comum tanto entre as crianças quanto entre os adultos.

Para as crianças mais novas, o comportamento ritual não representa nada, é simplesmente uma outra faceta da existência material das crianças, que faz parte da maneira como o mundo é, e elas não pretendem questionar o seu significado de forma implícita por meio de análises simbólicas. Isso não quer dizer que as crianças não formem associações específicas com respeito a certas práticas. Eles o fazem, mas não é até por volta de nove anos de idade que entendem explicitamente que o significado dessas práticas vai além do simples fazer (Toren 2002:119. 20, tradução livre).

Para transformar-se em um adulto, a criança deve fazer essa passagem: o ato perde a força intrínseca, que cede lugar para o significado do ato. Em um primeiro momento, a religião só pode ser entendida como uma prática. Mais tarde, no caso dos adultos e dos adolescentes, o significado torna-se massivo, sobrepondo a própria prática. À medida que a criança cresce, a prática vai se tornando subordinada ao seu significado. Como aponta a pesquisa de Toren:

Assim, a concepção adulta de acima/abaixo inverte o conceito da criança, o que foi inicialmente entendido como material e concreto passa a ser visto como uma expressão da explícita noção adulta de hierarquia, como uma espécie de imperativo moral: o princípio da hierarquia como derivado de uma interação entre posição social, antiguidade e gênero (1990:228, tradução livre). 
Assim, se ir à igreja era inicialmente entendido como algo no mundo prático, posteriormente esse movimento passa a ser entendido como a expressão de um pertencimento religioso, da adesão a um determinado credo.

\section{As redes sociais do frequentar a igreja}

Gostaríamos agora de retornar uma questão lançada anteriormente. Por que os adultos não permitem que as crianças frequentem cerimônias de outras religiões que não aquela que a sua família professa? Ora, os adultos não deixam as crianças circularem entre as igrejas porque, para eles, religião e igreja relacionam-se com um conjunto de ensinamentos, com uma teologia específica, enfim, com uma maneira de relacionarse com o sagrado. Além disso, para os pais, não se vai à igreja pura e simplesmente. $\mathrm{O}$ ato de ir à igreja implica, em grande medida, o aprendizado de um conjunto de ensinamentos teológicos daquela fé em particular. Por isso, importa sim qual igreja ou local de culto se frequente, uma vez que a definição de uma denominação religiosa é importante na medida em que as religiões divergem sobre as abordagens do fenômeno religioso ${ }^{12}$. Para as crianças pequenas, religião parece relacionar-se com o fato de ir a um edifício chamado igreja, nada mais. E por isso não há distinção entre as religiões: todas as igrejas são igrejas. Assim, quando as diferenças começam a transparecer, assim como as afirmações de pertencimento religioso, por volta dos nove anos de idade, nesse ponto sim podemos dizer que as crianças elaboram sobre as razões pelas quais ir à igreja, estabelecendo relações, como por exemplo: "Eu sou católico, então frequento a Igreja de São Sebastião". Nesse momento, elas estão mais próximas dos adultos em relação à religião que das crianças pequenas ${ }^{13}$.

Por outro lado, pode-se compreender por que as crianças querem ir às igrejas que seus pais não frequentam. Para elas, como já foi colocado, uma razão simbólica para ir à igreja não se coloca: ir é o ato em si, que preenche todas as perguntas; ir à igreja é somente ir à igreja e nada mais. Como afirma Toren:

$\mathrm{Na}$ acepção mais simples possível, isso significa que, para as crianças, o ritual não se refere a nada fora dele: beber kava é apenas beber kava e fazer a refeição é simplesmente comer. As atividades não são simbólicas no sentido antropológico convencional (1999:97-8, tradução livre).

Não se frequenta a igreja por uma razão simbólica, mas sim porque a mãe manda, porque os amiguinhos frequentam, porque o irmão mais velho leva. Trata-se apenas de fazer o que deve ser feito, o que todo mundo faz. Para as crianças, o que está por trás, ou seja, o conteúdo simbólico das religiões, não está em jogo. Ao contrário, o que está em jogo é o conjunto de atividades envolvidas no frequentar a igreja. Por fim, não importa qual das igrejas se frequente. $O$ que importa e tem consequências é ir à igreja com os amiguinhos ou a família. Tomando-se a visão de Toren (1999): 
para a criança, ir à igreja parece ser um "signo", um "significante", cujo "significado" se liga às relações com os amigos e familiares que ela estabelece no próprio ato. Já no caso dos adultos, tal ação se afirma como símbolo.

Em outras palavras, acima/abaixo para crianças mais novas é o que é chamado de "signo", isso é, um "significante" cujo "significado" são certas relações entre as pessoas no espaço; para adolescentes e para adultos, acima/abaixo tornou-se o que é chamado de "símbolo", aquele que contém o signo através de um processo de construção cognitiva, de modo que vem a significar uma diferenciação de status (Toren 1999:97, tradução livre).

Aqui retoma-se, então, a questão das redes sociais nas quais estão inseridas as crianças. Como já foi aludido anteriormente, as crianças aprendem sobre religião através das redes sociais, nas quais a família e as pessoas mais próximas têm papel primordial. É preciso salientar, entretanto, que apesar de a vida da criança estar limitada por um constrangimento material, essa materialidade se dá a partir de relações sociais que ela estabelece ao frequentar a igreja. Novamente recorremos a Toren:

O processo de aprendizagem é uma construção gradual e está amarrado, inicialmente, a certos objetos materiais, como a canoa, o pano na hora das refeições ou a própria casa, mas esses objetos materiais são artefatos culturais; eles não se referem apenas a si mesmos, mas às relações entre pessoas (Toren 1999:97, tradução livre).

Além da canoa, da vestimenta, da refeição e da casa, poderíamos acrescentar a igreja, que, segundo a perspectiva da criança, abrange o conjunto de pessoas e relações que estão implicadas no momento mesmo de ir à igreja.

Nessa mesma linha argumentativa, uma menina de dez anos de idade pontua: "A minha religião é católica e eu frequento a igreja todos os dias com minhas amigas e meus pais". Outra menina, de onze anos, escreveu: "Eu vou à igreja com minhas amigas". E uma garota da mesma idade conclui: "A igreja é bonita, tem o padre para celebrar a missa, tem muita gente. Eu vou à igreja com minhas colegas". Isso parece insinuar que, do ponto de vista da criança, muito mais que rezar ou aprender o catecismo, ir à igreja implica encontrar-se com as pessoas. Analogamente, quando pedi que desenhasse sobre a sua religião, um menino de dez anos de idade representou um castelo com duas bandeiras, várias torres e oito pessoas em pé próximas às construções (vide desenho abaixo). Quando lhe perguntei o que ele havia desenhado, ele disse: "É um castelo de pessoas carinhosas, carentes [sic]..." Indaguei a ele o que de religião havia nisso, quando ele simplesmente respondeu: "Tem gente. E é bonito". 

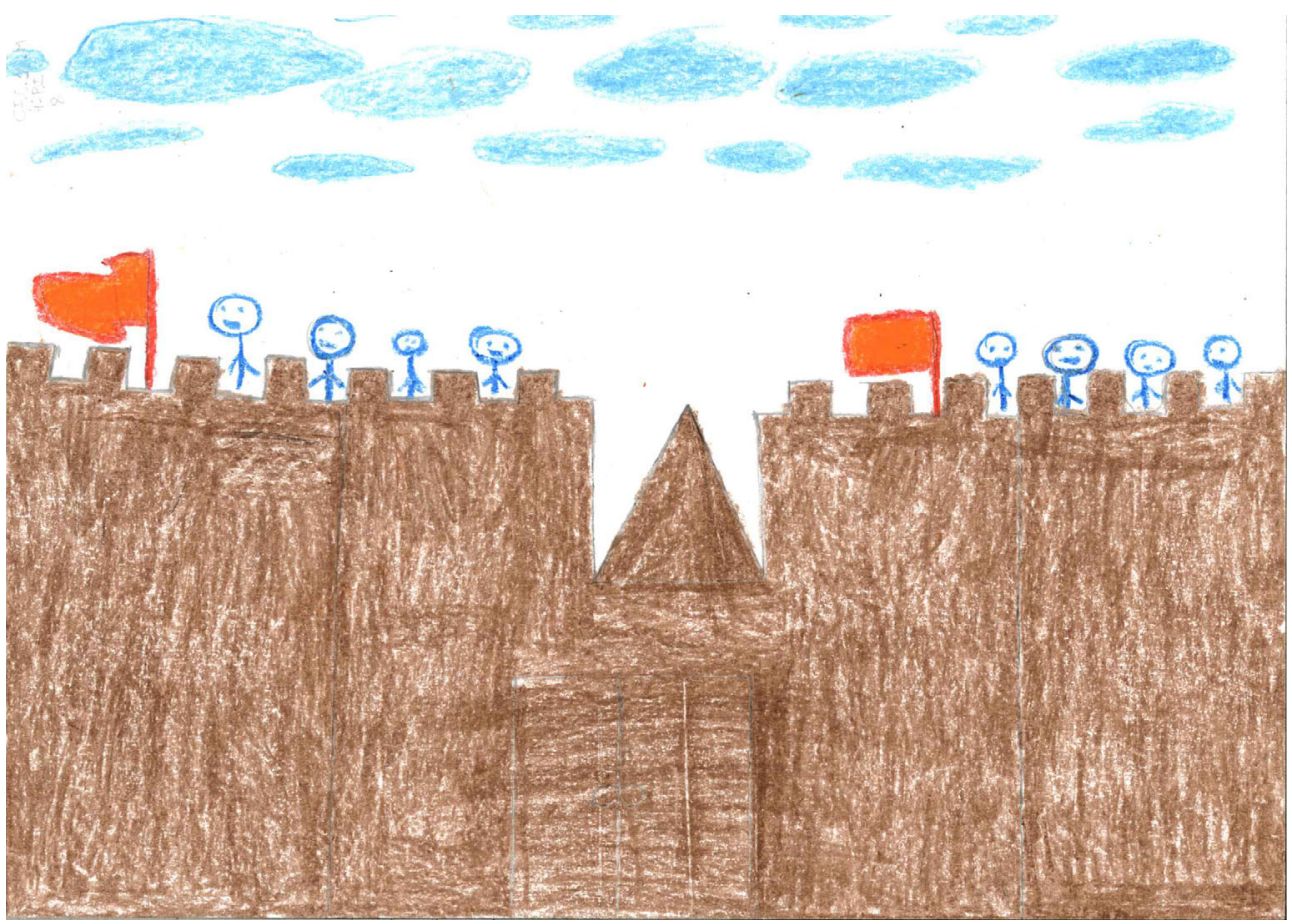

Complementarmente, uma menina de dez anos dizia-se insatisfeita com o novo padre da cidade porque ele deixava a "paz de Cristo" para o final da missa, o que desestimulava as saudações entre as pessoas. Esses exemplos, coletados dos desenhos cujo título deveria ser "A minha religião", parecem evidenciar a relação íntima entre as relações sociais e o frequentar a igreja, segundo a perspectiva infantil.

Partindo de tais exemplos, pode-se claramente perceber que o estudo das crianças não deve se limitar a elas mesmas. É fundamental pesquisar as redes de sociabilidade nas quais elas estão inseridas e através das quais aprendem a agir de acordo com os padrões da sua comunidade. Pesquisar as crianças sem excluir os adultos é o projeto compartilhado por Christina Toren (1999), Morton (1996), Mayall (1995): "Eu compartilho a visão de Toren de que estudar crianças como se seu mundo social fosse, de alguma maneira, separado dos adultos, é fornecer uma análise inadequada" (Morton 1996:05, tradução livre). Quando criança, as redes de sociabilidade parecem se restringir à família, aos vizinhos e aos amigos. Por isso, é importante observar, como fizemos nesse artigo, como se dá a inserção das crianças no mundo religioso, isso é, que preparativos envolve o frequentar a igreja, com quem e como elas vão à igreja etc. 


\section{Conclusões}

Para finalizar gostaríamos de tecer ou retomar três ideias: um questionamento da argumentação tecida; um problema metodológico com relação ao estudo das crianças; e um resumo da ideia geral do artigo, dada a necessidade de se aprofundar a discussão sobre o conceito de religião.

Interessante constatar que, para alguns adultos, a afirmação de que as relações sociais estabelecidas no seio da comunidade religiosa se afirmam como parte essencial do pertencimento religioso é aceita como verdadeira. Assim sendo, podemos nos questionar em que medida encontrar-se com os irmãos não é o que também estimula os adultos a comparecer à igreja. Acredito que a busca por essa convivência social de fato influi no comparecimento à igreja por parte dos adultos " embora pesquisar como tal processo se dá ultrapasse as pretensões deste artigo. No entanto, não posso deixar de mencionar o que um amigo, cujo pai é mulçumano e a mãe católica, certa vez me disse: que ele e seus amigos viviam "a religião mulçumana no nível da cultura". Com isso, ele queria dizer que apreciava e seguia, em algum grau, a prática religiosa, mas que não se interessava pelos ensinamentos morais da religião. Ele gostava de celebrar o Eid, de se reunir em família para comer depois do pôr do sol, de matar o carneiro para celebrar o fim do Hamadam. Disso, ele não abria mão. Mas o jejum ele não seguia, nem mesmo rezava o Corão. Consigo vislumbrar um paralelo interessante entre a postura desse meu amigo, que me parece representativa de uma parcela da população jovem mulçumana (principalmente dos que moram em países seculares) e a das crianças em Catingueira. Também elas vivem a religião na prática: interessamse pelos hinos, pelas procissões, pelas gincanas. Claro que podemos inquirir se, em alguma medida, não será também dessa forma que alguns dos adultos de Catingueira praticam a religião. Muitos não perdem a missa da festa do padroeiro, mas raramente se confessam ou pagam o dízimo. Não tencionamos afirmar que as pessoas frequentam os serviços religiosos por razões utilitárias ou por conveniência, como mostra parte da literatura especializada - que coloca, por exemplo, que as pessoas selecionam certos momentos para participar em uma festa de padroeiro (veja Fernandes 1982, Steil 1996, Martín 2001, que parecem concordar comigo). Quiçá seja a experiência religiosa no seio da comunidade: a igreja no sentido de ecclesia, importante tanto para os adultos quanto para as crianças. No entanto, é preciso investigar melhor como essa comunidade de irmãos se constitui para adultos e crianças (Velho 2007a; Pires 2007a).

Os antropólogos, como adultos, pensam através dos seus próprios paradigmas. Segundo Toren (1999:98), eles não incluem as crianças nas suas pesquisas justamente porque veem o mundo de uma perspectiva própria - e como não poderia deixar de ser, adulta. Dessa forma, quando os antropólogos dizem, por exemplo, que o ritual simboliza algo, eles estão partindo de um pressuposto adultocêntrico, na medida em que a experiência das crianças com relação ao ritual é totalmente diferente da 
experiência dos adultos. Toren argumenta que a perspectiva infantil do ritual está ligada à concretude dos elementos ali envolvidos, enquanto que, para os adultos, a materialidade do ritual existe em função do seu aspecto simbólico.

É porque nós, como adultos e antropólogos, tendo privilegiado as nossas próprias noções sobre as das crianças, não atentamos para o fato de que para todos o ritual deve representar algo distinto de si mesmo e que esse algo é passado através dos símbolos materiais, do comportamento (incluindo a linguagem utilizada etc.) que são requeridos em um determinado ato ritual (Toren 1999:98, tradução livre).

Tornar-se adulto implicaria, então, essa conversão de perspectivas, e é sobre isso que discorremos neste artigo. Pensamos o tornar-se adulto em termos religiosos como um processo de transformações, enfatizando as singularidades presentes no mundo adulto e no mundo infantil.

O que quisemos sugerir aqui é que as crianças não entendem o "porquê" de ir à igreja. Não que esse entendimento esteja acima das suas capacidades cognitivas. $O$ fato é que elas parecem não se perguntar esse "porquê", já que o significado das coisas não parece ser uma questão problematizada pelas crianças pequenas. Não estamos dizendo, entretanto, que as crianças não reflitam sobre a sua vida cotidiana. Sugerimos apenas que, para elas, os eventos religiosos importam em si mesmos, não demandam um significado oculto, metafórico ou simbólico no conjunto de práticas cotidianas. $\mathrm{O}$ ato encerra em si toda a sua complexidade ${ }^{14}$.

Tentamos pesquisar, a partir de uma perspectiva antropológica, o que as crianças de Catingueira entendem por religião e como tal entendimento vai mudando ao longo dos anos. Esperamos ter mostrado a viabilidade de explorar a pesquisa com crianças como forma de entrarmos propriamente na seara dos estudos da religião, ampliando a discussão sobre o conceito de religioso, já que como afirma Otavio Velho (2007b:317):

Boa parte das controvérsias religiosas hoje gira em torno da demanda moderna por uma definição clara e unívoca do religioso e a cada vez mais frequente contestação (pós-moderna?) das definições, na prática, desses limites.

Entender a perspectiva das crianças em relação à religião pode ser, assim, útil para a compreensão do fenômeno religioso. 


\section{Referências Bibliográficas}

ANTHONY, Sylvia. (1971), The discovery of death in childhood and after. London: Penguin Education.

ASTUTI, Rita; HARRIS, Paul L. (2008), "Understanding mortality and the life of the ancestors in rural Madagascar". Cognitive Science, $\mathrm{n}^{\circ} 32:$ 713-740.

ASTUTI, Rita. (2007), "Ancestors and the afterlife". In: H. Whitehouse \& J. Laidlaw (eds.). Religion, Anthropology and Cognitive Science. Durham, NC: Carolina Academic Press.

BERGO, Renata Silva; GOMES, Ana Maria Rabelo. (2009), "Eu sou muzenza": a aprendizagem no terreiro de umbanda. Trabalho apresentado na ANPOCS.

BOVET, Pierre. (1928), The child's religion. A study of the development of the religious sentiment. London and Toronto: J.M.Dent. and Sons Ltd.

BULlIVANT, Brian M. (1987), The way of tradition: life in an ortodox jewish school. Hawthron: Australian Council for Educational Research.

BUSHNELL, H. (1967), Christian nurture. New Haven: Yale University.

CAMPOS, R. B. C.; PAIVA JUNIOR, G. S.; SILVA, J. C. L. E.; MEDEIROS, S. G.; CISNEIROS, P. N. (2010), "Pesquisando o invisível: percursos metodológicos de uma pesquisa sobre sociabilidade infantil e diversidade religiosa". Teoria \& Sociedade, (no prelo).

COLES, Robert. (1990), The spiritual life of children. Boston: Houghton Mifflin Company.

DAVIES, Sarah. (1997), "Children's perceptions of the transmission of sikh culture/ religion that takes place through music lessons". Sikh Bulletin, n 14: 1-8.

DUARTE, Luiz Fernando Dias. (1986), Da vida nervosa nas classes trabalhadoras urbanas. Rio de Janeiro: Graal.

ELKIND, David. (1978), The child's reality: three developmental themes. Hillsdale / N. J.: Lawrence Erlbaum Association.

FALCÃO, Christiane Rocha; CAMPOS, Roberta. (2009), A imagem da criança. Reflexões sobre a presença da criança nas religiões. Trabalho enviado para ANPOCS.

FERNANDES, Ruben César. (1982), Os cavaleiros do Bom Jesus. Uma introdução às religiões populares. São Paulo: Brasiliense.

FRANCIS, L. J. (1987), Religion in the primary school: a partnership between church and state. London: Collins.

GARBARINO, James; BEDARD, Claire. (1996), "Spiritual challenges to children facing violent trauma". Childhood, vol. 3: 467-478.

GATES, Brian. (1976), The language of life and death: religion and young people. Lancaster: Tese de $\mathrm{PhD}$ em Antropologia, University of Lancaster.

(1982), "Children prospecting for commitment". In: R. Jackson (ed.). Approching world religions. London: John Murray.

GOLDMAN, R. (1964), Religious thinking from childhood to adolescence. London: Routledge \& Kegan Paul.

HARDMAN, Charlotte. (1999). "The ethics of children in three new religions". In: S. Palmer \& C. Hardman (orgs.). Children in new religions. Brunswick/New York/London: Rutgers University Press.

HARDY, A. (1965), The living stream: a restatement of evolution theory and its relation to the spirit of man. London: Collins.

(1966), The divine flame: an essay towards a natural history of religion. London: Collins. (1979), The spiritual nature of man. A study of contemporary religious experience. Oxford: Clarendon Press.

HAY, D.; NYE, R. (1996), "Investigating children's spirituality: the need for a fruitful hypothesis". The International Journal of Children's Spirituality, vol. 1, $\mathrm{n}^{\circ}$ 1: 6-16.

. (2006 [1998]), The spirit of the child. Revised Edition. London: Fount/ HarperCollins.

HELLER, David. (1986), The children's God. Chicago: University of Chicago Press. 
HYDE, K. (1990), Religion in childhood and adolescence: a comprehensive review of the research. Birmingham, Alabama: Religious Education Press.

JAMES, Allison; JENKS, Chris; PROUT, Alan. (1998), Theorizing childhood. London: Polity Press.

LALL, Surinder. (1999), "I know who God is". A study of sikh children's spirituality within various expressions of sikhism. Oxford: Farmington Institute.

MARTÍN, Maria Eloísa. (2001), Genuinamente correntina. Um estudo antropológico da experiência católica na festa da Virgem de Itatí. Porto Alegre: Dissertação de Mestrado em Antropologia Social, PPGAS/UFGRS.

MAYALL, B. (1995), "Children as a minority group: issues and prospects". Paper apresentado ao seminário Childhood and Society. London: Institute of Education.

MCCREERY, Elaine. (1996), "Talking to young children about things spiritual". In: R. Best e P. Lang (eds.). Education, spirituality and the whole child. London: Cassel.

MORTON, Helen. (1996), Becoming a Tongan. An ethnography of childhood. Honolulu: University of Hawaii Press.

NESBITT, Eleanor. (1993), "Children and the world to come: the views of children aged 8 to 14 years on life after death". Religion today, $\mathrm{n}^{\circ} 8$ (3): 10-14. Univesity of Leeds.

(2000a), The religious lives of sikh children: a coventry based study. Leeds:

(2000b), "Researching 8 to 13 years olds. Perspectives on their experience of religion”. In: A. Lewis \& G. Lindsay (eds.). Researching children's perspectives. Buckingham: Open University Press.

NOVAES, Regina. (2000), “O Brasil será um país evangélico?" In: F. Pinheiro \& P. R. Pires (orgs.). Próximos 500: perguntas que o Brasil vai ter que responder. Rio de Janeiro: Aeroplano.

O'KEEFFE, B. (1986), Faith, culture and the dual system: a comparative study of church and country schools. Lewes: Falmer.

OLIVEIRA, Pedro Ribeiro de. (1997), "Adeus à Sociologia da Religião Popular". Religião e Sociedade, vol. $18, \mathrm{n}^{\circ} 2: 43-62$

PIRES, Flávia F. (2003), Os filhos-ausentes e as penosas de São Sebastiãozinho. Etnografia da Festa da Catingueira/PB. Rio de Janeiro: Dissertação de Mestrado em Antropologia Social, PPGAS, Museu Nacional, UFRJ. Disponível em www.antropologia.com.br volume 22, (seção Trabalhos Acadêmicos).

(2004), "Quem vai comer da galinha? Ricos e pobres, católicos e crentes no sertão da Paraíba". Religião e Sociedade, Vol. 24, n.1: 65-84.

. (2005), "A lei é o Santo: mapeando as redes sociais da Catingueira". Teoria e Sociedade 15/01: 84-109.

. (2007a), Quem tem medo de mal-assombro? Religião e Infância no semiárido nordestino. Rio de Janeiro: Tese de doutorado em Antropologia Social, PPGAS Museu Nacional/ UFRJ.

(2007b), "Ser adulta e pesquisar crianças: explorando possibilidades metodológicas na pesquisa antropológica”. Revista de Antropologia, Vol 50, n¹: 225-270.

, (2009), "Quem tem medo de mal-assombro?". Revista Etnográfica, vol. 13, $\mathrm{n}^{\circ} 2: 291-312$.

ROBINSON, Edward. (1977), The original vision - a study of the religious experience of childhood. Oxford: The Religious Experience Research University, Manchester College.

SANCHIS, Pierre. (1997), "Pentecostalismo e cultura brasileira". Religião e Sociedade vol. 18, n²: 123-126.

SEMÁN, Pablo. (2000), A "fragmentação do cosmos": um estudo sobre as sensibilidades de fiéis pentecostais e católicos de um bairro da Grande Buenos Aires. Porto Alegre: Tese de Doutorado em Antropologia Social, Universidade Federal de Rio Grande do Sul.

. (2001), "Cosmológica, holista y relacional: uma corriente de la religiosidade 
popular contemporânea". Ciências Sociales y Religión. Revista de la Associacion de Cientistas Sociales de la Religión en el Mercosur, 3/3: 45-74.

STEIL, Carlos Alberto. (1996), O sertão das romarias. Um estudo antropológico sobre o Santuário de Bom Jesus da Lapa, Bahia. Petrópolis: Vozes.

TOREN, Christina. (1990), Making sense of hierarchy: cognition as social process in Fiji. London: The Athone Press.

. (1999), Mind, materiality and history. Explorations in fijian ethnography. London/New York: Routledge.

(2002), "Anthropology as the whole science of what it is to be human". In: R.G. Fox \& B. J. King (orgs.). Anthropology beyond culture. Berg: Oxford.

VELHO, Otavio. (2007a), "Epistrophê: do duplo vínculo às antinomias e de volta". Revista de Estudos da Religião - REVER, setembro: 123-144.

. (2007b), "Mistura ou diferença?". Mais realistas do que o rei. Ocidentalismo, religião e modernidade alternativas. Rio de Janeiro: Topbooks.

\section{Notas}

1 Este artigo foi apresentado de maneira preliminar no capítulo quarto da tese e é um aprofundamento da linha de pesquisa sobre religião e infância, trabalhada durante o doutoramento. Agradeço aos meus orientadores, Otavio Velho e Christina Toren, pelo apoio recebido e os isento de qualquer responsabilidade na confecção deste artigo. Agradeço também a George Ardilles da Silva Jardim pela revisão do manuscrito.

2 Naquele município a religiosidade sempre se mostrou um tema pungente, cujas conexões extrapolam a esfera do "religioso". A dissertação de mestrado (Pires 2003, veja também Pires 2004), por exemplo, trata da festa de São Sebastião, padroeiro da cidade, momento no qual a localidade recebe turistas e reinventa-se em tradições e efervescência social, sob as bênçãos do santo e da igreja católicos. Entender como os chamados "crentes" e espíritas kardecistas estão presentes nessa festa religiosa, a princípio católica, é um dos desdobramentos da dissertação.

3 Ao fazê-lo, deparei-me com a existência de seres chamados "mal-assombros" que podem ser, em alguma medida, intitulados de religiosos, uma vez que mantêm relações privilegiadas com o chamado "outro mundo", o mundo após a morte. Embora não seja o caso de aprofundarmo-nos aqui na ontologia dos medos, vale a pena, em poucas palavras, explicitar o contexto da pesquisa (para um maior detalhamento veja Pires 2007a, 2009). Para os adultos e os idosos, os "malassombros" são almas de pessoas falecidas. Para as crianças, por sua vez, eles são uma larga gama de seres e acontecimentos. Interessante notar que o medo dos "mal-assombros", altamente enfatizado pelos adultos e idosos, não o é pelas crianças. Isso se explica pelo fato de que para os adultos e, principalmente para os idosos, todos os "mal-assombros" são temíveis, uma vez que existe uma relação, a princípio inquestionável, entre eles e o diabo. Para as crianças as coisas não se passam dessa maneira. $\mathrm{O}$ "mal-assombro" assusta menos e quando o faz, a razão não pode ser colocada na sua associação com alguma entidade religiosa. Crescer em Catingueira implica, dentre outros aprendizados, entender que o "mal-assombro" é assustador pela sua associação com o demônio. Ao mesmo tempo, a pessoa vai se tornando católica, ou evangélica, ou espírita, de acordo com as experiências que ocorrem no decorrer desse processo.

4 Por uma questão de espaço, concentraremos nossa análise no material produzido pelas crianças, deixando as observações de caráter comportamental para outra oportunidade.

5 Convido o leitor a ler a tese (Pires 2007a) ou o artigo (Pires 2007b) para um aprofundamento das questões metodológicas na pesquisa com crianças e religião.

6 Os autores afirmam sua filiação a Alister Hardy (1965, 1966, 1979), um zoólogo darwinista da Universidade de Oxford que trabalhou com a "[...] hipótese de que o que ele chamou de 
'experiência religiosa' tem evoluído ao longo do processo de seleção natural, porque tem valor de sobrevivência para o indivíduo" (Hay \& Nye 2006 [1998]:22, tradução livre). Para eles, "Ao localizar a espiritualidade no organismo humano, coloca-se o foco sobre a infância e sobre a espiritualidade como intrínseca ao invés de ensinada" (Hay \& Nye 1996:13, tradução livre). Eles ainda afirmam que "Vamos, portanto, ser capazes de ir além de uma compreensão da espiritualidade da criança com base em 'conhecimento', para um domínio psicológico mais geral da espiritualidade como uma forma básica de conhecer, disponível para todos nós como parte de nossa herança biológica" (Hay \& Nye 1996:10, tradução livre) E concluem dizendo que "A espiritualidade é caracterizada aqui como uma forma natural da consciência humana" (Hay \& Nye 1996:6, também tradução livre). Espiritualidade, em seus termos, é algo mais abrangente que a religiosidade, e é encontrada em ambientes seculares. A pesquisa do doutorado distingue-se da pesquisa ora citada na medida em que aqui não estamos interessados em pesquisar as origens da religião ou da experiência religiosa.

7 Isso é, a soma das igrejas desenhadas, entendidas como templos (construções físicas), sem distinguir as diferentes denominações, embora com os dados coletados seja possível fazê-lo. 100\% corresponde ao número total dos desenhos realizados (297).

8 A não ser, é claro, aquela reunião das crianças que tem lugar no sábado pela manhã.

9 Nesta nota, talvez demasiado longa, discorro sobre a indumentária trajada pelos adultos ao frequentarem os serviços religiosos, a fim de tecer considerações sobre o mesmo aspecto do ponto de vista infantil.

Os "crentes" são conhecidos em Catingueira pelo uso de vestimentas formais. Para eles, é crucial se vestir bem para ir ao culto - e basta observar a indumentária masculina para se certificar disso. Os homens devem, sempre que possível, usar terno e gravata. Quando "passam para crente", os homens fazem um esforço para poupar parte do salário para tão logo adquirirem os itens enumerados. Camisas de mangas longas para dentro das calças é o mínimo que se exige, no caso dos homens, para se comparecer ao serviço religioso. Não importa o quão quente esteja o dia " regra válida também no caso dos meninos. As mulheres protestantes também escolhem com cuidado a roupa e se arrumam com esmero para o culto. Elas geralmente usam sandália baixa, saia abaixo do joelho, blusa com manga " todas as peças em cores sóbrias. Brincos, colares, pulseiras, batom, acessórios de cabelo ou esmalte nas unhas são geralmente desencorajados, embora certo grau de vaidade feminina seja permitido quando a menina ainda é muito jovem: por exemplo, o uso das cores vibrantes, entre as quais o rosa é permitido (e adorado pelas meninas) e, até mesmo, o uso de alguns acessórios, como uma bolsinha ou uns óculos de sol. Acredito que a exceção se justifique porque esses itens são vistos mais como brinquedos infantis que como artefatos representativos da vaidade feminina.

Para os católicos, por sua vez, também é crucial estar bem arrumado para frequentar os serviços religiosos. É comum as pessoas reservarem uma roupa especial, anedoticamente chamada de "roupa de ver Deus", para irem à missa. Os homens católicos não usam terno e gravata para ir à missa, mas certamente tomam banho e colocam uma das suas melhores roupas. Ouvi, mais de uma vez, pessoas dizerem que não iam à igreja católica, principalmente durante as festividades em honra do santo padroeiro, porque não tinham roupa nova para vestir (Pires 2003:62). Algumas pessoas também reclamam que na igreja católica todo mundo fica reparando na roupa alheia, e essa atitude acaba por inibir o comparecimento à igreja. Na igreja de São Sebastião, qualquer pessoa que não siga o padrão de vestuário pode ser vítima de olhares enviesados e/ou fofocas. No caso dos serviços religiosos especialmente destinados às crianças, temos um controle mais brando das vestimentas, tanto no caso dos adultos quanto no das crianças.

${ }^{10}$ Talvez as crianças sejam, por excelência, ecumênicas.

${ }^{11}$ Para usar a metáfora do espelho - e aqui agradeço ao parecerista anônimo da revista Religião e Sociedade que levantou esta ideia - seria preciso dizer que é a criança o espelho do adulto, um espelho invertido. O adulto seria, então, o outro da criança, e não o contrário. 
12 Alguns autores têm argumentado sobre o que é chamado de religião cósmica, ou realismo mágico, ou perspectiva cosmológica. Duarte (1986:243) denominou "mentalidade cosmológica"; Sanchis (1997), "lógica pré-moderna"; Oliveira (1997:49), "religião cósmica”; e, mais recentemente, Semán $(2000,2001)$, “visão cosmológica popular”. Donde se aponta para o fato de que na adesão a uma igreja e não a outra importam menos os motivos teológicos que os motivos de outras naturezas, como a trajetória individual ou familiar, motivos étnicos ou políticos etc. Isso permitiria às pessoas transitar entre igrejas sem maiores conflitos "religiosos". Nesse momento, estamos apenas querendo entender o porquê das crianças desenharem igrejas que os seus pais não frequentam e por que os pais não deixam as crianças circularem entre as igrejas, não considerando tal ato "correto". Uma pessoa, por exemplo, que começa a frequentar uma igreja evangélica vai ser vítima de comentários e fofocas até que ela se converta e se estabeleça enquanto "crente". Todo mundo sabe quem pertence a que igreja e a frequência com que comparecem ao local. Desse modo, apesar de existirem pessoas que circulam com certa liberdade entre as igrejas, esse não parece ser o acento local. Talvez o trânsito entre religiões possa ser observado com maior relevância nas cidades de grande porte.

${ }^{13}$ Como escreve Toren: "Para encontrar no ritual de 'beber o kava' o que os adultos encontram lá, as crianças têm de perceber que o que eles veem como o concreto é também figurativo de uma maneira específica: elas têm de perceber o 'beber o kava' como tão conectado à diferenciação de status, quanto ao ato de beber" (Toren 1999:94-100, tradução livre).

${ }^{14}$ De fato, ir à missa, ao culto ou à reunião espírita é algo que na prática envolve um conjunto de pessoas e diversas ações. Para a criança, o que parece importar é esse conjunto de relações sociais que a inserção religiosa propicia. Essas relações sociais estão enraizadas principalmente na família, mas também nas interações com vizinhos próximos e amigos. É principalmente através das relações com os membros da rede familiar que a criança aprende a se portar de acordo com o padrão cristão estabelecido em Catingueira.

Recebido em junho de 2008. Aprovado em dezembro de 2009.

Flávia F. Pires(ffp23279@gmail.com)

Antropóloga, professora adjunta do departamento de Ciências Sociais da UFPB, autora de diversos artigos publicados em periódicos científicos como Etnográfica, Religião e Sociedade, Revista de Antropologia, Mana, Cadernos de Campo etc. Vem trabalhando com os seguintes temas: religião, festa, criança e políticas públicas. 


\section{Resumo:}

Através da evidência etnográfica de que as crianças pequenas circulam (ou gostariam de circular) entre as diversas igrejas da cidade pesquisada e, tendo em vista que a religião parece ser definida por essas mesmas crianças como intrinsecamente ligada ao ir à igreja, este artigo " baseado em pesquisa de campo sobre religião na região do semiárido nordestino " trabalha com a hipótese de que a postura do adulto em relação ao sentido dado à religião é inversa ao entendimento infantil, tratando de pensar a categoria do simbólico não em sua suposta natureza ou permanência, mas como construída ao longo dos primeiros anos de vida de uma pessoa. Os dados foram produzidos através do uso de desenhos de crianças de três a treze anos de idade como instrumentos de pesquisa, além da observação participante.

Palavras-chave: simbólico, crianças, igreja, desenhos.

\section{Abstract:}

Through the ethnographic evidence that young children move (or would like to move) between the various churches of the studied city and given that religion seems to be defined by the same children as intrinsically linked to going to church, this article " based on fieldwork research on religion in the North-eastern semiarid region of Brazil " works with the hypothesis that the adult reverses the child understanding regarding the meaning given to religion, trying to think of the category symbolic not on its supposed nature or permanence, but as a category constructed during the first years of life of a given person. The data were produced through the use of drawings of children from three to thirteen years of age as research tools, as well as the participant observation.

Keywords: symbolic, children, church, drawings. 